\title{
Modeling the origin of parkinsonian tremor
}

\author{
Andrei Dovzhenok ${ }^{1}$, Leonid L Rubchinsky ${ }^{1,2^{*}}$ \\ From Nineteenth Annual Computational Neuroscience Meeting: CNS*2010 \\ San Antonio, TX, USA. 24-30 July 2010
}

Even though much is known about the biophysics, anatomy and physiology of basal ganglia networks, the cellular and network basis of parkinsonian tremor remains an open question. Multiple experimental data suggest that the physiological origin of parkinsonian tremor is different from the physiological origin of other parkinsonian motor symptoms [1]. However, the exact origin of the tremor genesis in Parkinson's disease remains unknown. A large body of experimental evidence supports the hypothesis, that the tremor arises due to pathological interaction of potentially oscillatory cells and circuits within the loop formed by basal ganglia and thalamocortical networks. We suggest a model of this circuitry, which helps to clarify this potential mechanism of tremor genesis.

There seems to be consensus that tremor is centrally generated, though several different hypotheses on the central tremor generation has being suggested (reviewed in [2]). Here we consider the basal ganglia-thalamocortical loop hypothesis. There is clear evidence for involvement of the motor thalamus, the primary motor cortex, the STN and pallidum in the tremor-related activity. These structures are connected, forming a loop, and each has separate limb representations. Lesions to any of them have been shown to abolish parkinsonian tremor. Thus the possibility of such a loop being functionally significant is very plausible. Moreover, thalamic hypotheses are at odds with analysis of spike correlations within bursts of thalamic activity during parkinsonian tremor [3]. Therefore, cortico-basal gangliathalamic loop origin of parkinsonian tremor appears to be quite reasonable.

We consider a conductance-based model of subthalamo-pallidal circuits (based on the models of STN and pallidal neurons, developed in [4]) embedded into a

\footnotetext{
* Correspondence: leo@math.iupui.edu

'Department of Mathematical Sciences and Center for Mathematical Biosciences Indiana University Purdue University Indianapolis, Indianapolis, IN 46202, USA
}

simplified representation of thalamocortical circuit to investigate the dynamics of this loop. We modulate the strength of the loop to represent the modulation of basal ganglia synapses by dopamine. A number of synaptic connections in the basal ganglia are known to be presynaptically suppressed by dopamine. Thus weaker connections in our model may correspond to healthy state or to the administration of dopaminergic medication, while stronger connections may correspond to the decreased level of dopamine in Parkinson's disease. The stronger connections ("lower dopamine") favor bursting in the tremor frequency range and this result is robust with the respect to what particular synaptic strength is changed. Similarly to this effect, when the feedback is completely removed, STN switches back to tonic or almost tonic firing. This happens for both possible locations of feedback interruption in the model - at the level of output of STN and at the level of input to pallidum and STN. However, the outcomes of these two possibilities are two different types of activity.

The proposed model supports the basal ganglia - thalamocortical loop mechanism of tremor generation. Under normal conditions the behavior of this loop is not oscillatory. The dopaminergic deficit of Parkinson's disease induces tremor-related oscillations in the loop. This suggests that thalamocortical circuits (which provide a feedback to basal ganglia) are changed in Parkinson's disease in such a way as to promote the birth of oscillations. Surgical intervention or dopaminergic medication in parkinsonian patients can break or weaken pathological feedback so that basal ganglia circuits no longer able to produce bursting. This may be the way of how the tremor is suppressed.

\section{Acknowledgements}

Supported by the National Institutes of Health grant 1R01NS067200 (NSF/ $\mathrm{NIH}$ CRCNS program). 


\section{Author details}

${ }^{1}$ Department of Mathematical Sciences and Center for Mathematical

Biosciences Indiana University Purdue University Indianapolis, Indianapolis, IN 46202, USA . ${ }^{2}$ Stark Neurosciences Research Institute, Indiana University

School of Medicine, Indianapolis, IN 46202, USA.

Published: 20 July 2010

\section{References}

1. Rivlin-Etzion M, Marmor O, Heimer G, Raz A, Nini A, Bergman H: Basal ganglia oscillations and pathophysiology of movement disorders. Curr Opin Neurobiol 2006, 16:629-637.

2. Rubchinsky LL, Kuznetsov AS, Wheelock VL, Sigvardt KA: Tremor. Scholarpedia 2007, 2(10):1379[http://www.scholarpedia.org/article/Tremor].

3. Zirh TA, Lenz FA, Reich SG, Dougherty PM: Patterns of bursting occurring in thalamic cells during parkinsonian tremor. Neuroscience 1998, 83:107-121.

4. Terman D, Rubin JE, Yew AC, Wilson CJ: Activity patterns in a model for subthalamopallidal network of basal ganglia. J Neurosci 2002. 22:2963-2976.

doi:10.1186/1471-2202-11-S1-P34

Cite this article as: Dovzhenok and Rubchinsky: Modeling the origin of parkinsonian tremor. BMC Neuroscience 2010 11(Suppl 1):P34.

\section{Submit your next manuscript to BioMed Central} and take full advantage of:

- Convenient online submission

- Thorough peer review

- No space constraints or color figure charges

- Immediate publication on acceptance

- Inclusion in PubMed, CAS, Scopus and Google Scholar

- Research which is freely available for redistribution

Submit your manuscript at www.biomedcentral.com/submit 